\title{
Unintended Consequences of Crisis Management
}

by László Csaba

This contribution attempts to decipher the largely unintended, still predictable consequences of crisis management in the global economy. In a series of improvised, case-bycase and unilaterally demand-focused measures, governments tried to extend the Keynesian arsenal to a system whose basic features are unlike those of the national economy. While the collapse of output and employment, on par with the Great Depression, could indeed be averted, conditions for the resumption of sustainable finance and growth have been undermined.

Dieser Beitrag versucht, die meist unbeabsichtigten, aber vorhersehbaren Konsequenzen des Krisenmanagements für die globale Ökonomie zu analysieren. Die Regierungen versuchten mit einer Reihe improvisierter und einseitig nachfrageorientierter ad-hocMaßnahmen, das keynesianische Arsenal auf ein System anzuwenden, das sich in wesentlichen Merkmalen von den nationalen Volkswirtschaften unterscheidet. Während ein Zusammenbruch der Wirtschaftsleistung und der Beschäftigung - zu dem es in der Weltwirtschaftskrise nach 1929 kam - verhindert werden konnte, wurde die Wiederaufnahme einer nachhaltigen Finanz- und Wachstumspolitik erschwert.

The years of 2007-2009 entered into economic history as the herald of a new era. While the process is still open ended, and the shape of recovery - U, L or $\mathrm{W}-$ is still in dispute, the modest recovery registered in major economies in the second and third quarters of 2009 allows us to conceptualise an end to recession, rather than engaging in the endless debates on doomsday scenarios and threats of depression. On the base of available statistics we can claim with reasonable certainty that the degeneration of the financial crisis, triggered by the collapse of the US subprime markets and the ensuing extinction of the investment banking industry, has not escalated into a depression along the lines of 1929-33 as feared by many. Contraction of global output is likely to be in the range of $3 \%$. GDP did grow in 2008 in all major economies except Japan, and forecasts - from those of the most pessimistic OECD to the more sanguine ones of the IMF invariably predict positive numbers for 2010. By 2011 most analysts expect a return to normalcy, i. e. of about $5 \%$ per annum growth of the global economy. 
The central claim of this paper is to challenge this unconditional optimism, which is derived mainly from the nature of the modelling exercise. If for no other reason, because of their mechanic composition, econometric models tend to presume - what in reality would be in need of theoretical substantiation - that once the worst is over, things will get back automatically to normalcy. The latter means in most of the cases the status quo ante.

As a matter of fact it is more than tempting to agree with this intuitive proposition, often formulated in elaborate technical form. If for no other reason, because the pre-crisis 15 years were rightly termed as the period of Great Moderation. ${ }^{1}$ In short, cyclical fluctuations have become smaller, fiscal policies were gradually converging to fairly orthodox positions, price stability for all practical purposes secured and thus growth sustaining and also trickling down. ${ }^{2}$ Even in such bottom cases as in Sub-Saharan Africa growth was over $5 \%$ per annum in 1993 2008 and inflation declined to single digit numbers. ${ }^{3}$ While policies actually conducted by major countries, most notably by the USA, Italy and France often strongly deviated from the theoretically advocated, sound positions, the broad agreement - which we may term the OECD policy consensus - seem to have survived, at least in the normative plain. Nobody close to government - let alone in actual government positions - advocated nationalisations, uncontrolled public debt, condoning inflation or sustaining high general government deficit. True, the Stability and Growth Pact of the EU was softened up in March 2005, but the change also included tightening in a number of areas, such as the ways deficit was to be accounted and highlighting the role of debt/GDP rates in the overall assessment. The latter indicator - having both a memory and predictive power over the leeway the government is going to have in the medium run - actually pre-empted the accession of most new member states to the single currency, contrary to their original intentions.

\section{From Great Moderation to Great Fears}

But times have changed since then, and former frontrunners have turned into laggards. Irish debt/GDP ratio tripled in 2007-2010, British debt levels doubled,

1 Stock, J./Watson, M.: Has the Business Cycle Changed, and Why?, in: NBER Macroeconomics Annual, 17 (2002), 157-237.

2 Sala $i$ Martin, X: The World Distribution of Income: Falling Poverty and Convergence Period, in: Quarterly Journal of Economics, 121/2 (2006), 351-397.

3 African Development Bank: African Development Report, 2009, Oxford, 2009. 
and America in 2009 exceeded the Maastricht debt ceiling, something that compares to wartime periods only, with gross debt forecast by the OECD to reach the staggering $110 \%$ by 2011 , unless quick remedial action is taken. Also the Baltic States, known inter alia for their prudent fiscal policy and negligible public debt/GDP ratios, have experienced a debt explosion, primarily accumulated by private households rather than the state. This was coupled with an unprecedented contraction of their output, 15-17\% in a single year in 2009. The European Commission warned of the danger of EU public debt growing over $110 \%$ by 2014 in a no-change scenario, and even President Obama, himself a proponent of fiscal stimulus in his election campaign, reckoned with a probability of a "double-dip recession", should the scenario of more of the same - pumping unlimited money in the economy - continue. ${ }^{4}$ And as it happens so often, the theoretical approval of policy misdeeds was no slow to emerge.

True, prior to the interpretation of policy changes a degree - perhaps too small a degree - of soul searching in the profession had started. The balance of power, previously showing the pre-eminence of new classicals and adherents of rational expectations and often even its more radical edition, the up until recently dominant fiscal creed of the efficient market hypothesis started to change in favour of more heterodox approaches. Let us note, those have never been extinct from the profession at large, although leading top economics journals and the most prestigious theoretical economics departments rarely cultivated this latter type of output.

First, the choir of old and new Keynesians have launched the "I told you so all the time" song. In a way, authors who have long been sticking to this position, such as Paul Krugman ${ }^{5}$ or Joseph E. Stiglitz ${ }^{6}$, whose productivity defies search programmes, can vindicate a degree of satisfaction, at least in the sense that their warning of the need to care about effective demand made its way back into policy-making, at the cost of more technical approaches and also at the cost of previously predominant views on the uses of rigid fiscal frameworks. It is instructive that one of the last immediate disciple of Keynes, Axel Leijonhufvoud ${ }^{7}$ called attention to the fact that contemporary problems are quite unlike the ones experi-

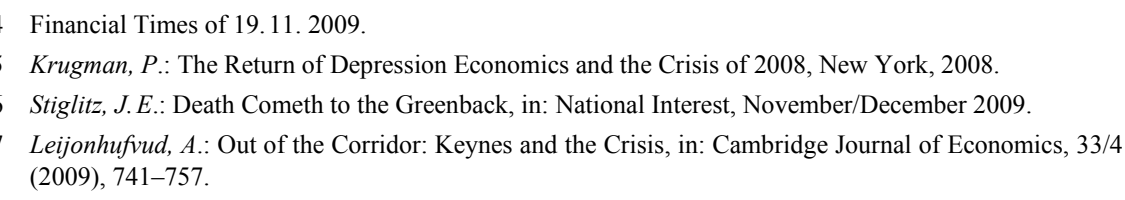


enced in the 1930s. Furthermore the changes in the transmission mechanisms and also in the logic of functioning in financial markets were such that simple demand management measures, never advocated in their rude form by Lord Keynes himself, can only be counterproductive, already in the medium run.

Second, long time critics of the mainstream of economic theory were also able to take a sweet revenge by pointing to the uses of their broader approaches. Perhaps the most influential among them was the book by Akerlof and Shiller ${ }^{8}$ calling for the reintroduction of psychology instead of outdated mechanics in the understanding of economic processes, in theory and practice alike. In a somewhat striking turn against their previous academic output they too turn towards advocating traditional Keynesian policy remedies for the crisis. Representatives of the old institutionalist school $^{9}$ have underscored the dangers of the reductionist, technicist approach that had dominated economic textbooks and financial analyses alike in the decades before the crisis. They point to the need for a broader, more sophisticated and institutionally informed approach in understanding the economy and offering policy advice.

So far, so good. But then a long list of new converts came, whom we should not necessarily cite by their name. Some of the claims are just journalistic excesses, others constitute rehashes of old and rightly forgotten theorems and theorists, Marx and Polányi included. What renders us to reflect on such propositions, as a third group, is that they are often espoused by top policy-makers and propagated at top international policy forums, such as G-20 meetings and EU Councils. While we do not consider it to be an academic job to process current policy commentary, it is hard to overlook that the discourse in the 2007-2009 period has become such that it has by and large undermined the previous OECD policy consensus. In other words, there are signs that fallacies are being considered as virtues and virtues are downgraded to old fashioned beliefs in doctrines that should no longer influence theories or even less so policy-makers.

If a later historian were to caricature the period of Great Moderation, policyrelevant economic theory would perhaps be reduced to four commandments. (1) Following the collapse of the Soviet Empire, the predominance of private property is unchallenged. Nationalisation is always a fallacy. (2) Demand manage-

8 Akerlof, G./Shiller, R.: Animal Spirits. How Human Psychology Drives the Economy and Why It Matters for Global Capitalism, Princeton, NJ, 2008.

9 Most prominently Hodgson, G.J.: The Great Crash of 2008 and the Reform of Economics, in: Cambridge Journal of Economics, 33/6 (2009), 1205-1221. 
ment is out, regulating money supply and reducing public debt is in. (3) Regulation, in general, leads to rent seeking and profiteering by ignorant bureaucrats. Deregulation allows for the invisible hand to sort out everything that needs to be sorted out, and this process allows for the spread of innovation and the trickle down of growth. (4) Market protection is generally a bad idea. All the more so, if it is rooted by the attempt to save jobs, which are not to be saved anyway. Flexible labour markets are the answer to structural and cyclical changes alike.

Whatever one may think about the merits or de-merits of this line of reasoning, it would be hard to deny the formative influence of the above sketched way of thinking on what we termed the OECD consensus on economic policy. While many countries - even in the EU - frequently violated these commandments, in normative terms this was seen much like individual Christians trespassing against the Ten Commandments in the course of their lives. Bad as it may be, but misdeeds hardly change the normative view of how things should be.

\section{Touching the Untouchable? Changes in Property Rights}

This academic certainty, by which academically trained and active economists tended to observe the complexity of the contemporary world, is by now gone. In all the four areas we see previous forefighters of the creed to act in reverse, and even attempting to justify, rather than rectify, their deeds on grounds of new or reinvented theories. The Pope may well sin, but never preach the value of being sinful. When the US government nationalises banks, protects American corporations from "hostile" takeover by foreigners, pumps money equalling to an entire year's GDP into the economy, closes down important segments of its market starting up with the job market, and allows for the ballooning of public debt while fighting calls for governmental restraint on fiscal and monetary stimulus as doctrinaire, this is perhaps a good analogy. The more it happens as part of a "new economic philosophy" rather than mere fire fighting, the further the analogy goes.

Likewise European governments have been rather prolific in indulging in a variety of state interventionism that was considered unthinkable say a decade ago. Perhaps the most frightening in this series of improvisation is the pronounced lack of any systemic thinking, even in the homeland of Ordnungstheorie und Ordnungspolitik. For it is perhaps the worst thing that may happen to any free society, if a government lapses into a series of unplanned and unintended interventions, which just multiply themselves like viruses and spread without any- 
body intentionally spreading them. This is an old insight of Ludwig von Mises ${ }^{10}$ from the study of command methods that proliferated during World War I and indeed avowedly served as models for Bolsheviks in conceiving their model. But worst of all, the study showed, the outcome may result from the unintended consequences of well-meaning democratic governments - an idea largely validated in the post-World War II period of statist economic policies in Britain, France and Italy.

This is not to launch a new crusade for privatisation along the lines of the 1980s, first conceived in the Thatcher-Reagan revolution, later followed up by the experience of post-communist countries. To be sure, there is no panacea for any economic matter, including efficient corporate governance under various institutional and policy settings, for all countries and all times, as the universalism of economic theory in its mainstream form would suggest and positively require. Still, references to the collapse of some private firms, as AIG, or the disputed outcomes of some privatisations, as those of the British Rail, by themselves do not suffice to question the relevance of broader and empirically tested insights on the generally more efficient workings of private firms, as indicated by many previous empirical studies. More recent studies of privatisation experience ${ }^{11}$ have also been supportive of earlier findings about the structurally superior performance of private corporations in most sectors and countries, provided the regulatory environment is appropriate, i.e. does not allow for monopolies and rent seeking. By contrast good performance of public firms can be observed in cases if they also work under competitive pressures of a contestable market and their budget constraint remains - or in most cases becomes - hard.

This overwhelming experience, grounded also in economic theory, does not let itself be swept away easily by references of individual less efficient and even positively unsuccessful privatisations. It might well be that nationalising a bank like Northern Rock or Llyods Insurance was the cheapest way to pre-empt the already unfolding systemic crisis and also, in theory, to save taxpayers' money whether this is true, especially in consolidated terms and audited by external bodies, will perhaps be known in decades rather than months, with reference to a combination of business and state secrets. But one may well wonder, if these exceptional arrangements translate into a new policy line.

10 Mises, L. v.: A Critique of Interventionism (1929), Aubum, AL, 1977.

11 Estrin, $S$. et al.: The Effects of Privatization of Ownership in Transition Economies, in: Journal of Economic Literature, 47/3 (2009), 699-728. 
At the time of writing, nobody can as yet have a clear answer to the fundamental question if, and to what degree, a paradigmatic change in terms of policy thinking is in the making. The British government goes out of its ways to explain the temporary nature of nationalisations. Likewise in the US similar propositions are being aired from the Obama administration. By contrast in Continental Europe statist traditions seem to have been experiencing a revival, at least on the discursive level. It would not make sense to follow the example of those who, on the base of newspaper articles, interviews and half-baked policy drafts try to identify the building blocs of new policy strategies. However it seems clear that the policy reaction, in the case of nationalisations, was largely spontaneous and has not followed any broader consideration. By the same token no ex ante policy of how to get out of business of crisis management has emerged. Furthermore even the broad contours of timing of measures putting an end to the series of improvisations remain unknown. The latter included pumping unlimited amounts of money in the economy and extending public ownership to spheres previously unknown. For this reason it is reassuring to read ever more frequent references, also by top policy makers, to the need to find what they euphemistically term an exit strategy from the mess, created in part by the crisis, in part by its (mis-)management.

What is truly intriguing from our perspective is not whether those projects will be forthcoming, as this is a matter of time rather than a matter of if. What is likely to be problematic is the semi-permeability of economic decisions: easy to do one way, next to impossibly the reverse way. For instance it is relatively easy to re-inflate an economy, while it is difficult to cool down inflationary expectations, even if agents are forward looking and well informed. None of the two traditional assumptions may hold in a post-crisis situation. For one, most of the "agents" are households, usually suffering from jobless growth, a period of 18 24 months following recovery of overall economic activity. In this period, when output already does grow, but employment does not, it is rational and justified to hold out and not to spend along the growth of household income - whether there is such growth is an empirical issue to be studied case by case. Second, not least as a consequence of the former, the perception of a lasting stagnation may survive way into the recovery period, not allowing for the type of adjustment the rational expectations model would forecast. For all those reasons neither spending, nor disinflation may follow the patterns expected in the model. ${ }^{12}$

12 It is a different, though in part related story, if and to what degree those models, especially of efficient markets ever held and if these contributed to upswings or to intransparency and the "irrational exuber- 
Likewise, nationalising a bank requires a stroke of a pen only. It can be done and has been done overnight, which is one of the big lures of this option. However, reversing the act is anything but straightforward. First, if recovery is slow and expectations remain pessimistic, buyers in all, but the most extreme cases, also tend to be restrained. Even if the government is truly intent on and committed to re-privatisation, buyers might not be forthcoming - an experience post-communist countries had much of in the 1990s. If buyers are forthcoming, heavy policy choices are yet to be made, which are unlikely to remain uncontested even under the best of circumstances - meaning a pro-privatisation public mood, which is anything but given at the time of writing. First, if and to what degree financial investors may have the upper hand. This seems trivial, but many governments, also in the West, consider banks as a type of family silver, especially if they serve broad segments of the population like house owners. And second, in the case of strategic investors, the question if the buyer is involved in a hostile takeover, or in a mere restructuring, often of radical brand, implying major layoffs and slimming cure for local financial institutions, the politics of the decision is/will be hard to eschew.

What has been said implies that broad state involvement in the ownership and actual running of banks is a phenomenon which is unlikely to go away as quickly and painlessly as contraction of output goes away in any business cycle theory. Involvement of the state hand, according to theory and experience alike, does involve the presence of criteria other than those of improved allocative efficiency in the decisions on lending, restructuring, employment and many other fundamental issues of macroeconomic significance. The lack of catching up of Europe to the USA as envisaged by the Lisbon Agenda of the EU for the current decade, is a clear indication, that the European models of social market economy are less likely to produce quick efficiency gains and sustainably high growth rates than the models where decision over resource allocation are less constrained by public policy considerations. This in turns implies that demand management and the ensuing record levels of public debts are not innocent sidelines to a generally robust and healthy recovery, which is sure to come.

ance" in the words of Greenspan as of 1996, of capital markets in the US and elsewhere, an issue theorised in some detail in Csaba, L.: Crisis in Economics?, Budapest, 2009, Chapter 2. 


\section{How to Manage Demand?}

We have seen above that demand management is back in vogue. This is unsurprising, since neo-Keynesianism has been part and parcel of academic good manners, and DSGE models, widely used by central banks, allow for this type of reaction to the crisis. Moreover Keynesianism has always interpreted itself as economics of the crisis. Last but not at all least, similarly to the 1930s, much of the spontaneous reactions of policy-makers follow, intuitively or otherwise, the Keynesian recipe, perhaps in its simpler versions.

Let us add, that Keynesianism, although by and large discarded in academia - at least in the mainstream departments - has never lost its appeal entirely for policy makers. For instance the Stability and Growth Pact of the EU, calling for surpluses in good times but deficit spending at bad times, does follow the original Keynesian maxim. True, governments in most of the EU tended to apply those insights in an asymmetric fashion, i.e. spending at bad times without making savings at good times. The very fact that governments, primarily but not exclusively in the EU, but also in the G-20 have been acting in a coordinated fashion, and so did central banks when cutting their interest rates and making other measures of monetary easing, contributed to avoiding the worst: escalating trade wars along the lines of the 1930s triggering a depression.

In evaluating the latter the established insight should be invoked, namely that fiscal stimulus may have a short term impact on the trend rate of output at best, as any growth theory, neoclassical or endogenous, would testify. Moreover quantitative estimates ${ }^{13}$ also indicate that short term multipliers may, already in the medium run, be overshadowed by negative multiplier effects. Likewise monetary easing is unlikely to produce long term effects, if growth is contingent, at the end of the day, on factors like innovation, efficiency of allocation and the quality of business climate.

The above measures perhaps deserve some credit in warding off the worst, such as competitive devaluations, proliferating market protectionism, and generally the beggar thy neighbour policies of the 1930s. These measures - together with the nature of globalised finance ${ }^{14}-$ also contributed to the much smaller than feared contraction of the global economy - in the range of $3 \%$ in 2009 - and a

13 Freedman, C. et al.: Fiscal Stimulus to the Rescue? Short Term Benefits and Potential Long Term Costs of Fiscal Deficits, Washington, DC, IMF Working Paper, 09/255, November 2009.

14 Mishkin, F.: Globalization and Financial Development, in: Journal of Development Economics, 89/2 (2009), 164-169. 
recovery already in 2010 and 2011 according to each major forecasting agency. We shall address, at the end of this paper, if this hyper-optimism is warranted, and if yes, under what conditions.

While acknowledging the virtues of firefighting, an academic can never be content without looking into the longer term repercussions of the same measures. If for no other reasons, because analyses of the Great Depression, including the book of Ben Bernanke $e^{15}$ published not long before his nomination to the chairmanship of the FED, have called our attention to the ephemeral nature of monetary and fiscal interventions. Moreover he also highlighted the dangers inherent in policy courting - central bank following market sentiment rather than following its own declared objective of sustaining price stability and thus economic calculability in the medium to long run. Joining the broad theoretical and historical overview offered by Issing et al. ${ }^{16}$ he also highlighted the limitations to what monetary policy can attain in fostering the trend rate of output. While the ECB has managed, by and large, to act on these theoretical insights, the FED, the Bank of Japan and the Bank of England have not followed suit. By entering into a wave of unweighted, uncontrolled and unmeasured rate cuts, they have done exactly what textbooks - and also the two monographs we cite - have always warned them not to. If a central bank follows market sentiment, it becomes just one of the many players, losing its privileged position as a trend-setter. Second, it loses the sovereign instruments of monetary policy: a close to zero prime rate no longer carries any information over governmental policies. It does not stimulate savings in monetary form, thus it induces speculation - e.g. in precious metals, commodities or just any foreign asset, thus it is no longer able to stimulate the domestic economy. This lesson was well documented by the lost decade of Japan. ${ }^{17}$ Third, if verbal interventions and forecasts remain ineffectual, which is often the case, even the remnants of central bank credibility will be gone.

Should one think about the burgeoning literature on central bank independence and credibility ${ }^{18}$ the above listed unintended side-effects look truly weighty. If for no other reason, because of the difficulty of reversing a process in which deep seated convictions and perceptions, most notably trust, credibility and the

15 Bernanke, B.: Essays on the Great Depression, Princeton, NJ, 2005.

16 Issing, O./Angeloni, I./Gaspar, V.: Decision Making in the European Central Bank, $2^{\text {nd }}$ ed., Cambridge/New York, 2004

17 Saxonhouse, G./Stern, R.: The Bubble and the Lost Decade, in: World Economy, 26/3 (2003), 267-281.

18 De Haan, J./Masciandaro, D./Quityn, M. (eds.): Does Central Bank Independence Still Matter?, European Journal of Political Economy, Special Issue, 24/7 (2008). 
ability to trend-set, i.e. the fundamental features of modern central banking are at stake. Whatever were the reasons behind the decisions, we may know for sure that the probably much too intimate relationship between markets and central banks $^{19}$, that used to characterise the period of Great Moderation, are unlikely to return soon. The more central banks get involved in supervising the banking industry, as most recent proposals in the USA would have it, the higher is the probability of their permanent loss of status as honest brokers and representatives of public interest only. In turn, the efficacy of their intervention is likely to be judged under a plethora of angles and considerations, including political, regional, employment, and who knows what other factors. Against those the return to a central bank, which is fully independent of daily politics - as the statutes of the European Central Bank stipulate - and which has a single target in its objective function, i.e. headline inflation (HICP in EU parlance), will be next to impossible to master.

It is not very difficult to see that giving up depoliticisation of monetary policy is not an intended consequence of crisis management. Still, the more we have to reckon with the lasting presence of big quantities of money pumped into the OECD economies to avert the collapse of output, the more we see only lukewarm efforts at fighting the consequences of crisis management, the higher is the probability of a relapse into a lasting re-politicisation of monetary policies. Under this angle calls for monetary policy to be subordinated to employment goals, regional policies, fostering government projects, and the entire longforgotten old-fashioned statism will be extremely difficult to avert. The more we have conservative governments like that of President Sarkozy and Prime Minister Berlusconi, with activist and interventionist economic agendas high on their overall policy profile, the graver the danger to be spread across the entire political spectrum is likely to be. Against this background the debate about the timing and scope of the exit strategy, conducted in public between the IMF and $\mathrm{ECB}^{20}$ whether or not the time has already come to act, is obviously of subordinate relevance at best. For if monetary policy gets re-politicised, there is no way back from the joint and combined effects of fiscal and monetary easing and the ensuing stagflationary periods.

19 Greenspan was known to have understood his task to preempt any potential bubble that may hurt Wall Street, which was a peculiar - biased - interpretation of the role of public policy as a warden of common good.

20 Világgazdaság of 25.11. 2009. 


\section{Revival of Blind Faith in Capacities of the State?}

One of the further unexpected consequences of haphazard and mostly improvised crisis management in OECD countries has been the gradual and mostly subconscious return of beliefs most of us thought to have been long forgotten in the past three decades. The collapse of the Soviet Empire and the related beliefs in central planning seem to have sealed in the dustbin of history the beliefs in an omnipresent and omnipotent state administration. True, it would be hard to deny that the other extreme of non-interventionism also emerged in the present decade, even when legal arrangements of the US would have positively called for it. This strange couple could be observed in some of the markets, while fostering nonprudent behaviour on other markets, most notably in the subprime mortgage market. ${ }^{21}$ Once that done - as the source proves in detail - further regulations to avoid brinkmanship would have been required in the related markets as well as in the techniques of risk assessment. In reality, exactly the opposite policy was adopted, as a conscious choice.

Let us note at the very outset: the widespread talk about unfettered capitalism and unregulated markets seriously misses the point, namely that (a) without particular forms of state intervention positively discouraging prudent behaviour of financial institutions and (b) without equally straightforward and professed policies of non-intervention, allowing for the accumulation of fat profit in the shadow zone of activity, not limiting cases of collusion, the subprime crisis could never have erupted. ${ }^{22}$ For in this combination of semi-regulations risks were socialised while profits privatised, and the dangers of the game covered by free market talk and references to actual and perceived financial innovations, spreading the risks across the globe. The jury is still out over who and when should have intervened to stop the bubble from bursting. On the other hand it is equally well represented in the literature that two decades of the Greenspan period implied and actually delivered a shield from any bubble to burst. As a result fear and caution have been extinct from market players - ironically as an outcome of FED policies aimed at avoiding the burst of the bubbles. It is also true that some segments of the capital markets, most notably OTC deals and hedge funds tended to be under-regulated. But the latter constitute only a minor part of the problem,

21 Györffy, D.: The Enduring Lure of Socialism: the Political Economy of the Subprime Crisis, in: ZSE, 7/2 (2009), 250-275.

22 Swan, P.L.: The Political Economy of the Subprime Crisis: Why Subprime was so Attractive to the Creditors?, in: European Journal of Political Economy, 25/1 (2009), 124-132. 
against the spread of dubious deals and patterns of behaviour in the tightly regulated sector. As shown in the source material cited, profit maximising agents ruthlessly exploited loopholes and mistakes in regulation, as well as could count on the grandfatherish behaviour of regulators whenever it came to matters of collusion (cf. below).

This fragmentary summary of the literature, that can be extended at will, may indicate that the financial crisis should, at least in part, be ascribed to state failure, in terms of the unintended consequences of policies, which positively fostered - as of low interest rates and privileged housing loans ${ }^{23}-$ as well as of policies, that might have been enacted but were not. If one recalls the OxleySarabanes Act, passed in reaction to the Enron crisis in 2001, as well as the wide range of potential intervention tools in the hands of authorities overseeing capital markets, one may not neglect the responsibility of those who have not acted, although the room for action was indeed given. Not allowing for the collusion, in which rating agencies were involved, when they evaluated corporations, while their returns/fees were related to the value of the firm they evaluated, has always been part and parcel of the legal understanding in America. It is a different story why so elementary requirements were not applied in actual practice. ${ }^{24}$ The answer can perhaps in part be related to the overall hands off ideology of the Bush administration coupled with the reign of the efficient markets hypothesis in the academic financial literature at the cost of other, more realistic and more sophisticated views such as behavioural finance.

Under this angle the issue of regulation might be seen under a different angle. For one, everybody seems to agree on the need of regulation. On the other hand, if our above observation holds, at least in part, it might be legitimate to ask, how the same organs of the state, whose actions - by omission and commission have been at the root of the crisis itself, can and should be entrusted with more regulatory tasks.

The collapse of communism in the East and the collapse of Bretton Woods in the West have contributed to the justified doubts in the abilities of the state to control macro- and microeconomic processes in the detail. If we abstract away from

23 Compassionate conservatism implied a declared intention to multiply the number of home owners, especially from among the worse-off.

24 The revised version of the Walker report in the UK introduces a series of measures in terms of collusion, risk management, executive pay and individual responsibility in line with the normative view unfolded in the main text, but falls short of governmental regulation of the petty detail as feared by many (cf. A guide to the Walker report, in: Wall Street Journal, online edition of 26.11. 2009). 
cases of criminal negligence, currently investigated in dozens of cases in the US and Europe alike, one may arrive at the question of limits to state capacity. The more one reflects on the nature of modern finance based to a large degree on derivatives and other forms of immaterial transactions and putting numbers of future/expected values, the less one is inclined to see how a bureaucrat can, even in theory, have the capacity and oversight to regulate such multispeed and multilayer processes. As the latter take part basically in the internet, rather than any locality, furthermore that markets tend to operate round the clock, 24 hours and 7 days, it seems impractical to believe that anybody could stop and channel them. The ghost is already out of the bottle.

And here we may well enter into yet another unintended consequence of crisis management. The more the state amasses competences and regulatory prerogatives, and the more it wishes to impose upon non-cooperating agents of various sorts, the lower is the efficiency of those interventions that might work only if the intervener were in reality a "perfectly informed agent" of equilibrium economics. As a result, the higher flying are the expectations, voiced by politicians, the media and the public, in terms of "putting the house finally in order", the lower the efficiency and the more incalculable the outcomes of such interventions are likely to be. One needs a very strong imagination to conceptualise a case where governments can launch, run and modernise entire industries, from car production to insurance, let alone innovation or financial intermediation in the complexity we have come to know in the last quarter of the century. The more governments follow their ambition to "put things in order", the less relevant and less credible their exit strategy may prove to be. In turn, the trust of financial markets and thereby the ability to fund these and other - perhaps competing - projects of the private sector will remain limited. In turn, the relocation of economic dynamism to emerging markets, and definitely away from ever more sclerotic and overregulated Europe, will become a fact of life, as experienced already in the 1970s and 1980s.

What we observe now is a double danger in terms of regulation. First, regulation will be more top-down and thus less efficient, than it would be optimal for recovery to sustain, it is likely to proliferate in forms and areas where justification on usual public intervention grounds - i. e. creating externalities - is less than certain. Second, those regulations, which are meant to be temporary, will become lasting constituents of the new system. Enhancing capital requirements across the board may well improve solidity, but will decrease the ability to lend, thus recovery is bound to slow, and the new bubble might already be in the blowing, as 
several observers of financial markets have already suggested. Applying Basel Two requirements may decentralise risk management, but may also be procyclical, thus once again contributing to stagnation. Protecting jobs (of insiders) is known to limit new entry, i.e. the creation of jobs for outsiders, for example by micro and small businesses yet to be created. European rates of unemployment have been notoriously high in the 1980s and 1990s for precisely those reasons. Limiting financial innovation, for fear of the misuses widely reported, may well translate into less intermediation, especially to the less competitive segments of the global economy, which translates directly into less embodied technological progress and lower rates of economic activity. Let us recall that the idea of spreading risks is not only about creating new markets to greedy investment bankers. The other side of the same coin is the provision of access to funding to clients of various sorts, who would otherwise not qualify for access to capital markets, or would not even be bankable. The more we accept the relevance of finance in the broad context of development, ${ }^{25}$ the more we may be concerned about recent initiatives to constrain financial innovation in general and the use of instruments spreading risks geographically and across sectors in particular.

Should the above described turn in policy practices receive theoretical backing, a relapse into the statism of the 1950s and 1960s is a likely outcome. This would assign tasks to the governments which they are incapable of mastering, from bolstering innovation to creating productive jobs. As a yet another unintended, but foreseeable, consequence, the limited administrative capacity, needed to meet tasks inherent to public policies, as for example environmental protection, ensuring rule of law and sustainable public finance, will be endangered by the proliferation of conflicting tasks whose numbers and nature is likely to be beyond reasonable policy and efficiency control. By the same token the quality of governance in key areas is likely to deteriorate, not least due to the impossibility of meeting an unlimited amount of tasks, often following different and even conflicting priorities and rationalities, such as of short term political versus long term economic nature.

\section{Towards Patriotic Economic Policies?}

One of the truly perplexing outcome of the policy drift described above has been the return of the theory and practice of market protectionism in most advanced

25 Chin, M. D./Ito, H.: What Matters for Financial Development? Capital Controls, Institutions and Interactions, in: Journal of Development Economics, 81/1 (2006), 163-192. 
economies, the EU itself included. It is perhaps unnecessary to list the measures that were making headlines. President Sarkozy's call to relocate car production from new member states to France, the German government's battle with both the US and the EU Commission to save Opel, the intensification of "buy national" campaigns as well as the spread of measures related to consumer fears all point in the direction of reacting to the crisis in the old manners. Recurring attempts to re-impose customs duties and other restrictions of Chinese and Vietnamese textile and clothing are just among the better known examples.

This is not to claim that in the pre-crisis period the functioning of the Single European Market had been impeccable. The Commission website has long been publicising a scoreboard, by the country and the sector, singling out malpractices of individual member states in a number of areas. However, as the examples listed above may illustrate, market protection, both against competitors from within the EU and also from WTO members, has been gaining currency and political respectability. The foot-dragging on the further reform of common agricultural policy in the post-2014 period, under the new financial guideline is also a case to the point. Pronouncements of some major policy-makers as well as of academic authorities call into question the wisdom of export-oriented strategies, a line that has moulded the evolution of all successful emerging economies over the past 35 years.

It would be excessive to depict the picture of overall protectionism rising on the horizons of the contemporary world economy. The very fact that 2010 and 2011 are seen as years of recovery, renders such a pessimistic scenario unlikely. However, owing to the uncertainties that follow from the fragile nature of economic revival, burdened with the costs of state activism described in the preceding pages, the slow growth scenario is not out of question especially for Europe. The financial crisis has also shown the fragility and imperfections in the financial sector of the new EU member states. In turn, most recent forecasts no longer count on a "return to normalcy", i. e. of a 4-5\% per annum GDP growth in Central and Eastern Europe once the crisis is over. Fragility of finances, low levels of savings, burgeoning public debt and the crowding out effects of growing debt service burden altogether make a slower rate more likely to emerge.

Under this angle the small open economies in the EU might be particularly heavily hit if the contours of new protectionism, dubbed sometimes as "patriotic economic policies" gain currency across the EU. It goes without saying that a longish period of fiscal consolidation, which is likely to set the tone for the medium run all across Europe, is not the time when reviving the domestic markets could 
compensate for the sluggish growth of external demand. For this reason it is the common European interest to sustain the accomplishments of European integration, including stable currency, the single market and the common fiscal framework that would induce governments to undertake those consolidation measures, which are needed for sustainable growth to return anyway. Expanding the Eurozone, even under temporarily softening of the criteria, may be the cheapest way to stabilise economies like those of the Baltics and Bulgaria, which have shown fiscal restraint and convergence in the pre-crisis period. The less principal members, such as France, Germany and Italy, actually meet the numerical criteria for EMU, and far not only and after the financial crisis, the less is the justification of rejecting such an unconventional option for the new and fragile members, which account for a fragment of financial turnover in the EU and are therefore in no position to endanger monetary stability there. The alternative of big, government-led bailout packages, extended to Latvia, Hungary, Romania and Serbia, does not seem to count among the big success stories, whose presence per se would render unconventional suggestions unrealistic. ${ }^{26}$

Last but not at all least one should react to the fact that most market protective measures are being triggered by concerns about jobs. On this account two observations may be due. First, as shown in the 1970s and 1980s, structural imbalances in general, and on the labour market in particular, simply do not lend themselves to cyclical remedies of demand management. The bigger is the fiscal stimulus, the higher the ensuing inflation in the medium and long run.

Second, the crisis has shown that the major improvement of European employment record in the 2000-2007 period, leading to a halving of the rate of unemployment in such chronic problem cases as Spain, Poland and Slovakia ${ }^{27}$ has been built on precarious footings if cyclical slump could undo those gains in a single year. This calls attention to the need of more implementation of the European Employment Strategy as well as to the need to invest more into human capital, especially in vocational training and the development of social skills, allowing also less qualified and elder persons to engage in lifelong learning.

If there is anything new in seeing the revival of employment-related pressures for protectionism it is in line with the more recent insights of economic theory on

26 The very fact that EU members had to resort to IMF standby arrangements, and also that EU Commission was involved in close cooperation with the Washington twins, was itself already a deeply unconventional policy initiative.

27 ECB: Statistics Pocket Book, Frankfurt/M., 2009, 44. 
trade openness. These works ${ }^{28}$ call attention to the relevance of institutional quality in making open markets productive and efficiency enhancing, rather than reverting the conventional wisdom and putting the cart in front of the donkey, as relapse into protectionism and import substitution would do.

\section{Towards a New Theory or a New Policy Mix?}

What has been proposed until now is a set of observations where we tried to square established economic theories with a set of nonconventional measures of crisis management actually implemented by leading economies of the globe in response to the 2007-2009 financial crisis. We have not found instances that would indeed have indeed justified the frequent public calls for a change in economic paradigm, as was the case in the aftermath of the Great Depression, or following the first and second oil price hikes of 1973 and 1979. In the first case the rise of state led models and later in the 1950s the spread of Keynesianism, in the second case the emergence of more open economy models and the spread of neoliberal approaches of various brands could be observed.

By contrast, the events of 2007-2009 could relatively well fit to existing theories of regulatory capture and state failure, especially if advances on asymmetric information are also incorporated in the theoretical frame. The set of policy measures, improvised rather than conceived by the major governments, does not add up into a new and sustainable policy package. At the time of writing major policy making bodies, such as the FED and the ECB, discuss merely the optimal timing of the exit strategy from unconstrained fiscal stimulus, not whether such an exit is necessary at all.

One of the additional unintended consequences of crisis management has been the insight that contingency planning is back on the main stage. For if the attractive theories proclaiming - once again - the end of the business cycle, or the ability of efficient markets to self-regulate, can no longer be taken seriously, then the ability to prepare, in theory, psychology and policy arsenal, for yet another slump, should be considered as an exigency for any solid government.

Second, it has been found, once again, that academic acclaim, not least because of the very different success of indicators of the academia from those of policy making, may not provide the best and most useful sort of advice decision-makers 
may need at times of difficulty. Policy relevance of competing research paradigms should perhaps be considered, in terms of funding and other forms of public appreciation.

Third, the economics discipline itself has been confronted, once again, with the drift between its own standards and performance criteria on the one hand, and its ability to interpret and sometimes even influence/change for the better spontaneously unfolding real world macro-economic processes on the other. While the compulsion to test theories on the ground is a platitude for any physicist, chemist, biologist, medical doctor or psychiatrist, and so is the need to feed back experimental findings into the theory, such kind of organic interchange had been interrupted and often positively denied in mainstream economics. It might be time to heed the insights of those who have long reminded the profession of the dangers inherent in the Samuelsonian shift in academic methodology and theorybuilding, ${ }^{29}$ which lay at the root of drift between economics and the sciences built on experimentation, testing and historic continuity.

Fourth, while top journals of the economics profession in their vast majority proudly reject to get engaged in reflections interpreting the financial crisis and its potential implications for theory building, it is unlikely that the marked changes on the demand side should, in the medium and long run, have no effect on the supply side. Once public institutions, corporations, banks and the media positively require qualifications able to decipher and improve misdevelopment in finances and in economic life (at macro- and household levels alike), the supply of economists and by implication of economics departments is likely to adjust its output to those manifest changes. It is likely to accelerate the pluralisation of the discipline which has been revived already during the aftermath of the previous financial crisis of 1997-99 and allow for more institutionally informed approaches, such as the Austrian school, to regain their traditional academic respectability.

Fifth, crises have always the benefit of shaking overconfident assumptions, such as the idea that economics, based on general equilibrium theory, has already answered all major questions, and only limited and technical improvements were in place. ${ }^{30}$ This point was made, in a perhaps even more assertive tone, by Nobel winner Robert E. Lucas in a relatively recent programmatic article claiming the

29 McCloskey, D.: The Secret Sins of Economics, Chicago, 2002.

30 Blanchard, O.: What Do We Know about Macroeconomics what Fisher or Wicksell Did not Know?, in: De Economist (Amsterdam), 148/5 (2000), 571-601. 
following: "My thesis in this lecture is that macroeconomics in this original sense has succeeded: Its central problem of depression-prevention has been solved, for all practical purposes, and has in fact been solved for many decades. ${ }^{, 31}$ While this boasting may well sound as naive as the oft cited similar claims made by Lord Kelvin on the eve of the Heisenberg-Einstein revolution in quantum physics, this was equally meant and taken quite seriously by most of the academic profession until the past few years. Adherents of the rational expectations school tended to substitute empirical testing by re-iterating their own assumptions and claims.

Likewise, observing the crisis may prompt us to give up the currently dominant view that economic policy can and should be understood and modelled by the theory of rational expectations. ${ }^{32}$ Moreover, the recurrence of crises with the notorious - and probably inevitable - inability of both theorists and forecasters to provide policy-makers and the public even with an intelligent guesstimate about the timing and size of those, may question the prime importance of predictive power being the major success indicator of academic soundness. By giving up this major cornerstone of the positive economics paradigm economists may become more open to a variety of heterodox approaches. In turn our ambitions as well as self-congratulatory tone of analyses might well be lowered, and softer, more probabilistic approaches, currently reigning in most of the other sister disciplines, espoused again, as it used to be the case in economics as well until the late 1980s.

We do not claim to know the future, and our tentative theoretical and policy conclusions offered in this essay may well trigger controversy. What we observed fits well into the apt - and often used - dictum of Friedrich August von Hayek on the nature of market order: outcome of human action, but not of human deliberation. For this reason we should by no means be surprised to observe this in the most recent turn of economic history.

31 Lucas, R.E.: Macroeconomic Priorities, in: American Economic Review, 93/1 (2003), 1-14, here 1.

32 Sargent, T./Wallace, N.: Rational Expectations and the Theory of Economic Policy, in: Journal of Monetary Economics, 2/2 (1976), 169-183. 